\title{
ELECTRICAL PARAMETER MAPS OF CANADA
}

\author{
Juanjo Ledo ${ }^{1,2}$, Alan G. Jones ${ }^{1}$ and James A. Craven ${ }^{1}$ \\ ${ }^{1}$ Geological Survey of Canada, Ottawa, Canada, ${ }^{2}$ Now at: University of Barcelona, Spain
}

\section{INTRODUCTION}

As discussed by Jones and Craven (this volume), deepprobing electromagnetic studies, using the naturalsource magnetotelluric (MT) technique, may offer a rapid, inexpensive method of area selection for diamondiferous provinces. Towards that goal, we present continental scale electrical parameter maps for Canada at various lithospheric depths; herein for $70 \mathrm{~km}$ and 120 $\mathrm{km}$ depths. There are currently insufficient measurements across the Archean craton regions of Canada for these maps to be used as a useful guide for regions that are terra incognita, but this paper serves as an indication of what is achievable with more data.

\section{MT DATABASE}

Over the last two decades deep-probing electromagnetic data, using the natural-source magnetotelluric (MT) technique, have been acquired at over 1500 locations under the auspices of LiTHOPROBE (Clowes et al., 1992, 1998, 1999). Taken together with other MT data acquired by the Geological Survey of Canada, there exists MT data at approx. 2,000 sites across Canada. Most come from LITHOPROBE's series of ten transects, each of which is focused on representative geological features of Canada that represent globally significant tectonic processes. These transects span the country from Vancouver Island to Newfoundland and from the U.S. border to the Yukon and Northwest territories; and geological time from $4 \mathrm{Ga}$ to the present. However, the majority are in southern Canada. The GSC studies include MT data from remote northern locations, such as across the Rae-Hearne boundary in the western Churchill province and on central Baffin island.

\section{APPLICATION}

From these data it is possible to construct regional-scale maps of various electrical parameters for various depths within Canada's sub-continental lithospheric mantle. We present maps of averaged electrical resistivity and of electrical anisotropy, identifying regions of high resistivity and of high anisotropy. Correlating this information with the known locations of Archean cratons, we can peculate where there may be prospective areas for diamond exploration.

\section{MAP CONSTRUCTION}

The various parameter maps were constructed as follows:

\section{RESISTIVITY MAPS}

1. At each site, the rotationally invariant averaged MT apparent resistivity and phase response functions, as a function of frequency, were transformed to approximate resistivity-depth profiles using the Niblett-Bostick transform (Niblett and SaynWittgenstein, 1960; Bostick, 1977; Jones, 1983). This transformation is very approximate, and is not to be confused with formal one-dimensional inversion of the MT responses that result in a true resistivity-depth profile.

2. The resistivities at particular depths were spatially smoothed, with a nearest neighbour algorithm, using routines in GMT.

3. Maps were constructed of the smoothed contoured resistivities, again using GMT, and we present here maps at $70 \mathrm{~km}$ and $120 \mathrm{~km}$ (Figure 1).

\section{ANISOTROPY MAPS}

1. At each site, the maximum difference of the Bostick transforms calculated between two orthogonal directions was derived. This gives a qualitative idea of regions with important electrical conductivity lateral changes. For a one-dimensional (1-D) Earth, this value must be zero. We calculated the average difference between orthogonal Bostick transforms for six different angles between $0^{\circ}-90^{\circ}$.

2. The resistivity differences at particular depths were spatially smoothed.

3. Maps were constructed at various depths of the resistivity differences, and of the differences scales by the average resistivity. We present maps at 70 $\mathrm{km}$ and $120 \mathrm{~km}$ (Figure 2). 

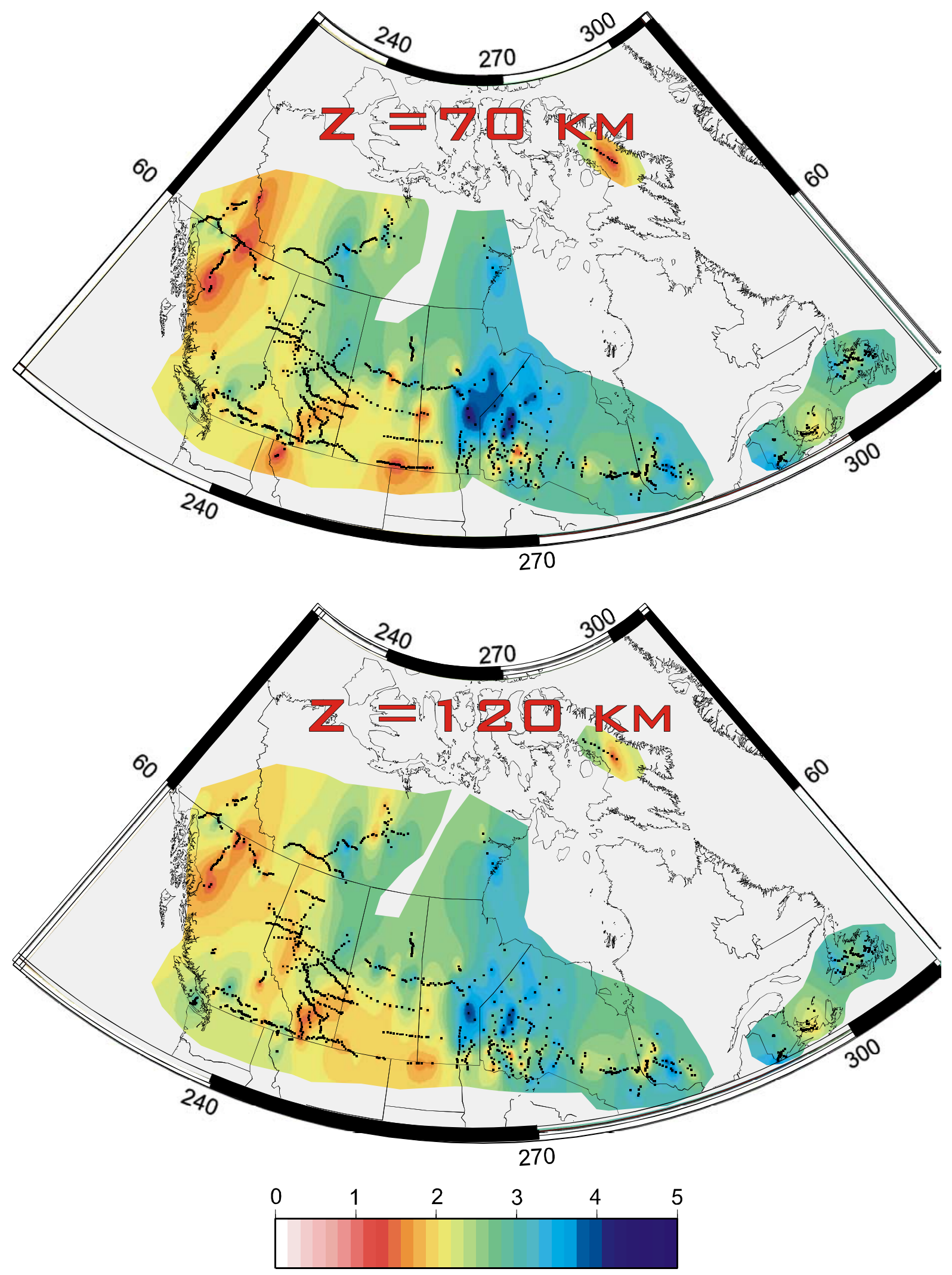

Log Resistivity (Ohm.m)

Figure 1: Averaged resistivity maps at $70 \mathrm{~km}$ and $120 \mathrm{~km}$ 

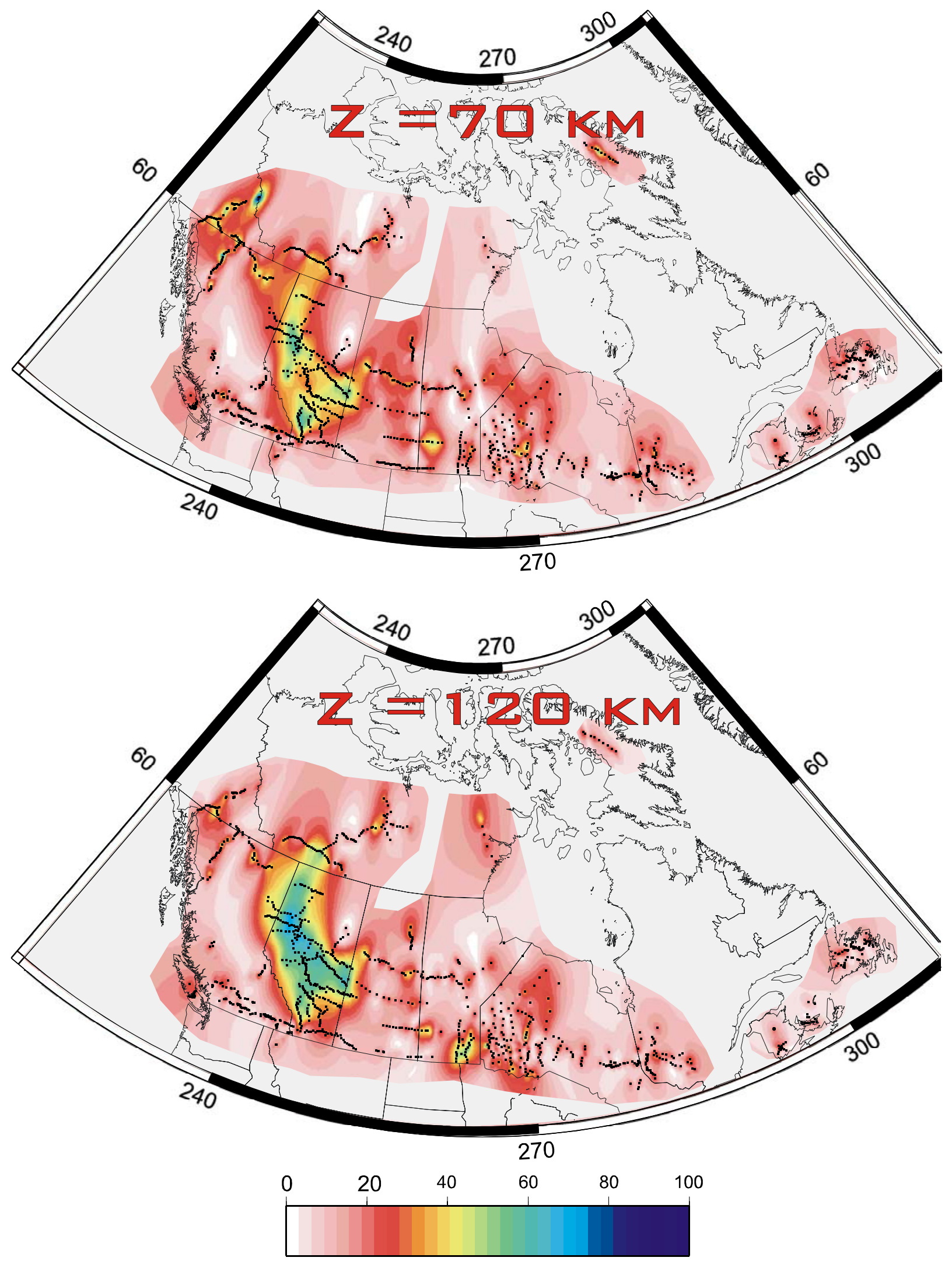

Percentage

Figure 2: Percentage maximum resistivity anisotropy maps at $70 \mathrm{~km}$ and $120 \mathrm{~km}$ 


\section{INFERENCES}

These maps represent a first attempt to display the available Canadian MT data in a form amenable to interpretation on a continental scale. LITHOPROBE data acquisition was predominantly across orogens, and in the more accessible parts of Canada along road networks, rather than to provide systematic coverage of the Canadian Shield. The Slave component of the SNORCLE transect, and the Western Superior transect, provide most of the data on the Archean. Apart from those, recent GSC studies across the Snowbird Tectonic Zone (Jones et al., 2002a) and in the central part of Baffin Island (Jones et al., 2002b; Evans et al., 2003a, 2003b) are the only modern MT data to be acquired in cratonic regions of Canada. Clearly, far more MT data need to be acquired and added to the Canadian database.

These maps must be interpreted with caution. Their construction was performed using an approximate 1-D transformation from MT responses as a function of frequency to resistivity-depth profiles. This transformation is known to be poor, and formal 1-D inversions will be undertaken in the future. Also, where the Earth is not 1$\mathrm{D}$, then misleading results can occur, much like diffraction problems in seismic reflection data. However, the scale of the maps and the smoothing applied should make such issues less severe.

We can draw some conclusions from the maps. The Central Slave Mantle Conductor (CSMC) of Jones et al. (2001) is visible in the $120 \mathrm{~km}$ resistivity map (Figure 1). The North Caribou Terrane (NCT) conductor of Craven et al. (2001), in the western Superior province, does not appear in the $120 \mathrm{~km}$ map, but is interpreted to lie somewhat deeper than the CSMC. Both of these regions are diamond prospective.

The mantle west of Hudson Bay is highly resistive, as discussed by Jones et al. (2002). If the arguments of Jones and Craven (this issue) regarding the necessity of high carbon content are valid, then this region is poor as a likely diamondiferous province.

The mantle beneath Alberta represents the most highly anisotropic in Canada, which may reflect lithospheric shearing resulting in high anisotropy. However, the central Superior province displays weak anisotropy in the maps, contrary to observations summarized in Mareschal et al. (1995), suggesting some further work is necessary.

\section{ACKNOWLEDGEMENTS}

Many many people, students, contractors, University academics, government staff and industry, contributed to acquiring the data in the Canadian MT database shown in these maps. It would be an injustice to try to record them all here, as we will surely forget someone. We thank you all!

The bulk of the financial support for data acquisition came from Natural Sciences and Engineering Research Council of Canada (NSERC), through grants to the LITHOPROBE project, and the Geological Survey of Canada (GSC), through budgets assigned to LITHOPROBE, EXTECH (III and IV), NATMAP and PAS. Other financial and logistical support came from the U.S. National Science Foundation's Continental Dynamics program, Indian and Northern Affairs Canada, DeBeers Canada Exploration Inc., Kennecott Canada Exploration Ltd., Diavik Diamond Mines Inc., BHP Billiton Diamonds Inc., Falconbridge Ltd., Royal Oak Mines and Miramar Mining Inc.

JL wishes to thank the GSC and LITHOPROBE for providing resources for his PostDoctoral Fellowship activities in Canada during 1999-2002.

\section{REFERENCES}

Bostick, F.X., 1977. A simple almost exact method of MT analysis. In: Workshop on Electrical Methods in Geothermal Exploration. U.S.G.S., Contract No. 14080001-8-359.

Clowes, R.M.,Cook, F.A., Green, A.G., Keen, C.E., Ludden, J.N., Percival, J.A., Quinlan, G.M. and West, G.F., 1992. Lithoprobe: new perspectives on crustal evolution. Can. J. Earth Sci., 29: 1813-1864.

Clowes, R.M.,Cook, F.A., Hajnal, Z., Hall, J., Lewry, J., Lucas, S. and Wardle, R., 1999. Canada's Lithoprobe project (collaborative, multidisciplinary geoscience research) leads to new understanding of continental evolution. Episodes, 22, 3-20.

Clowes, R.M.,Cook, F.A., and Ludden, J.N., 1998. Lithoprobe leads to new perspectives on continental evolution. GSA Today, 8, 1-7.

Craven, J.C., R.D. Kurtz, D.E. Boerner, T. Skulski, J. Spratt, I.J. Ferguson, X. Wu and R.C. Bailey, 2001. Conductivity of western Superior Province upper mantle in northwestern Ontario. Geol. Surv. Canada, Current Research 2001-E6, 6 p.

Evans, S., A.G. Jones, J. Spratt and J. Katsube, 2003a. Central Baffin electromagnetic experiment (CBEX): Phase 2. Geol. Surv. Canada Current Research, accepted.

Evans, S., A.G. Jones, J. Spratt and J. Katsube, 2003b. Central Baffin electromagnetic experiment (CBEX) maps the 
NACP in the Canadian arctic. Phys. Earth Planet. Inter., submitted.

Jones, A.G., 1983. On the equivalence of the "Niblett" and "Bostick" transformations in the magnetotelluric method. J. Geophys. 53: 72-73.

Jones, A.G., Ferguson, R., Chave, A.D., I.J., Evans, and McNeice, G.W., 2001, The electric lithosphere of the Slave craton. Geology, 29, 423-426.

Jones, A.G., D. Snyder, S. Hanmer, I. Asudeh, D. White, D. Eaton and G. Clarke, 2002. Magnetotelluric and teleseismic study across the Snowbird Tectonic Zone, Canadian Shield: A Neoarchean mantle suture? Geophys. Res. Lett., 29 (10), doi: 10.1029/2002GL015359, 10-1 $-10-4$.

Jones, A.G., Snyder, D., and Spratt, J., 2001, Magnetotelluric and teleseismic experiments as part of the Walmsley Lake project: Experimental designs and preliminary results; Geological Survey of Canada Current Research, 2001-C6.

Mareschal, M., Kellett, R.L., Kurtz, R.D., Ludden, J.N. and Bailey, R.C.. 1995. Archean cratonic roots, mantle shear zones and deep electrical anisotropy. Nature, 373: 134-137.

Niblett, E.R. and Sayn-Wittgenstein, C., 1960. Variation of the electrical conductivity with depth by the magnetotelluric method. Geophysics, 25: 998-1008.

Contact: AG Jones, Geological Survey of Canada, 615 Booth St., Ottawa, Ontario, Canada, K4M 1E3 E-mail:

ajones@nrcan.gc.ca 